\title{
Areǧena (plur. Ireǧenāten, fém. tareǧenat, fém. plur. tireǧenātīn)
}

M. Gast

\section{Q OpenEdition}

1 Journals

Édition électronique

URL : http://journals.openedition.org/encyclopedieberbere/2584

DOI : 10.4000/encyclopedieberbere.2584

ISSN : 2262-7197

Éditeur

Peeters Publishers

\section{Édition imprimée}

Date de publication : 1 janvier 1989

Pagination : 878-879

ISBN : 2-85744-324-2

ISSN : 1015-7344

Référence électronique

M. Gast, « Areǧena (plur. Ireǧenāten, fém. tareǧenat, fém. plur. tireǧenātīn) », Encyclopédie berbère [En ligne], 6 | 1989, document A266, mis en ligne le 01 décembre 2012, consulté le 14 octobre 2020. URL http://journals.openedition.org/encyclopedieberbere/2584; DOI : https://doi.org/10.4000/ encyclopedieberbere. 2584

Ce document a été généré automatiquement le 14 octobre 2020.

(c) Tous droits réservés 


\title{
Areǧena (plur. Ireǧenāten, fém. tareğenat, fém. plur. tireğenātīn)
}

\author{
M. Gast
}

1 Vient de la racine reğenet : « associer ensemble deux races... (le sujet étant une personne ou un animal) » (Foucauld 1952, IV, 1604); le terme de « race» ici étant pris dans son sens le plus large : association d'un bélier à laine et d'une brebis à poil ras, association d'un cheval quelconque avec un pur sang arabe, d'un Anglais avec une Française, d'un Blanc avec une Noire, d'un noble avec une plébéienne, etc.

2 Areǧena: désigne aujourd'hui, plus précisément en Ahaggar et dans les zones sahéliennes que fréquentent les Imūhay ou Imosay un individu issu d'une lignée associant d'une part, des nomades blancs arabophones, d'autre part des Imūhay (touaregs) berbérophones. Les Iregenâten sont parfaitement reconnaissables au fait qu'ils vivent selon les mêmes coutumes que les autres Imūhay auxquels ils se rattachent, mais qu'eux seuls sont toujours demeurés bilingues. Leur vocabulaire arabe est très proche de celui des Mauritaniens biyedan. L'étude linguistique de l'arabe de Ireğenāten pourrait être riche d'enseignement sur leurs affinités culturelles et historiques.

3 Les Ireğenāten se divisaient autrefois en Ireğenāten sețțäfriin (noirs) et Ireğenāten haggarnīn (rouges). Ces dénominations de couleurs n'ont aucune relation avec la couleur de leur peau, mais pourrait bien être significatives au niveau de la parenté et de certains droits. En effet, les premiers seraient issus selon Lhote, d'un ancêtre du Gourara et de femmes Ibottenāten (touarègues) et les seconds issus de Deremsa («arabe») et d'Ibottenāten. Cette particularité ethnique semble avoir conforté leur endogamie. Il ne pratiquent pas d'alliance avec les autres Imūhay. Cependant il est facile à des religieux ou des arabophones non Imūhay de prendre femme chez les Ireğenāten. Une étude approfondie de leurs généalogies et de leurs structures sociales pourrait certainement définir si cette tausit se caractérise par une double filiation unilinéaire qui leur permit de connaître et de faire prévaloir d'une part leur patrilignée remontant à des fondateurs arabes, et d'autre part leur matrilignée, établissant des alliances de ces derniers avec des femmes touarègues, en l'occurrence tabottenat (des Ibottenāten). 
Les Ireğenāten se rapprochent en ce sens des Isseqqamaren qui, eux aussi, se disent "arabes» alors qu'il sont de culture touarègue, tout en conservant une double appartenance que les études en cours ne permettent pas encore d'appeler «bilinéraire ». Ils ont comme les Isseqqamaren d'excellentes aptitudes au commerce et aux tâches manuelles, toute chose que les Imūhay de tradition ont toujours dédaignée.

Ils nomadisent de l'Adrar des Ifoyas à l'Ahnet jusque dans l'erg Chech. De par les contrats de protection (temazlayt)* qu'ils avaient été obligés de nouer avec les Kel Ahaggar, leurs segments matrilignagers payaient des redevances à des chefs de segments matrilignagers suzerains de l'Ahaggar (voir Benhazera p. 158 qui constate sans les expliquer ces coutumes). On a cru que ces redevances étaient une tiuse (tribut) alors que les Ireğenāten se refusaient à être considérés ainsi que les Isseqqamaren comme imyad tributaires. Assimilés de fait les uns au tobol (unité politique) de l'Adrar, les autres à celui des Kel Ahaggar, ils avaient le même statut intermédiaire que les Isseqqamaren, c'est-à-dire qu'en tant que descendants "d'Arabes", ils refusaient la vassalité. Après 1917 (date de la défaite de Kaocen), les Ireğenāten de l'Ahaggar se fixent avec leurs nombreux troupeaux au Tamesna ainsi qu'une bonne partie d'Isseqqamaren et d'autres tausit de l'Ahaggar. La sécheresse du Sahel de 1970 à 1974 décime la totalité de leurs troupeaux les obligeant à revenir près de Tamanrasset avec les réfugiés nigériens et maliens.

En Ahaggar on dénombrait en 1915, 50 à 60 hommes Ireǧenāten; en 1938, 358 personnes Ireğenāten; en $1949: 435$ personnes Ireǧenāten et en 1960/61:699 personnes Ireğenāten (après l'Indépendance les recensements par tausit n'ont plus été recherchés).

Depuis le retour des pluies et des pâturages en zone sahélienne (1975-1976) certains d'entre eux ont tenté de retourner sur les lieux de prédilection que représentent les espaces du Tamesna (au nord du Niger) pour recréer des troupeaux en achetant des bêtes sur les marchés de Tahoua, Agadez de In Gall. En 1977, tous les autres survivent près de Tamanrasset grâce aux secours du Service des sinistrés et des salaires qu'il gagnent dans les différents services d'embauche de la Wilaya de Tamanrasset. Malgré les offres anciennes du gouvernement nigérien, les Ireğenāten ont toujours préféré garder la nationalité algérienne.

\section{BIBLIOGRAPHIE}

FOUCAULD Ch. de, Dictionnaire touareg-français, Imprimerie nationale, 1952, t. IV, pp. 1604-1605. FOUCAULD Ch. de, Dictionnaire abrégé touareg-français de noms propres, Paris, Larose, 1940, p. 206. BENHAZERA M., Six mois chez les Touareg du Ahaggar, Alger, Jourdan, 1908, pp. 157-158. LHOTE H., Les Touareg du Hoggar, Paris, Payot, 1955, pp. 202, 238-239. BRIGGS L.-C, Tribes of the Sahara, Cambridge, Harvard University Press, 1960, p. 162. 
INDEX

Mots-clés : Sahara, Sociologie, Tribus 